Fanum

Sociológico

\section{Forum Sociológico}

Série II

$20 \mid 2010$

A pobreza, pluralidade de olhares e de intervenções

\title{
A saúde e sua relação intrínseca com o organismo e o ambiente
}

Inês Meira e Ana Patrícia Carvalho

\section{(2) OpenEdition}

Edição electrónica

URL: https://journals.openedition.org/sociologico/512

DOI: $10.4000 /$ sociologico. 512

ISSN: 2182-7427

Editora

CICS.NOVA - Centro Interdisciplinar de Ciências Sociais da Universidade Nova de Lisboa

\section{Edição impressa}

Data de publição: 1 junho 2010

Paginação: $75-82$

ISSN: 0872-8380

\section{Refêrencia eletrónica}

Inês Meira e Ana Patrícia Carvalho, «A saúde e sua relação intrínseca com o organismo e o ambiente», Forum Sociológico [Online], 20 | 2010, posto online no dia 27 setembro 2012, consultado o 29 março 2022. URL: http://journals.openedition.org/sociologico/512 ; DOI: https://doi.org/10.4000/sociologico. 512

Este documento foi criado de forma automática no dia 29 março 2022.

(c) CICS.NOVA 


\title{
A saúde e sua relação intrínseca com o organismo e o ambiente
}

\author{
Inês Meira e Ana Patrícia Carvalho
}

\section{Uma perspectiva ecológica da saúde}

Se a saúde resulta do equilíbrio dinâmico entre o organismo e o ambiente, com a iminência das alterações climáticas, a crise ecológica irá repercutir-se inevitavelmente numa crise na saúde: "O conceito ecológico de saúde pressupõe harmonia e compatibilidade entre o organismo e o ambiente" (Hanari, 1999: 92).

A ecologia, como conceito, surgiu em 1866, quando Ernst Haeckel a definiu como o total de relações dos organismos para com o mundo exterior (Hanari, 1999: 2). Por sua vez, o conceito de promoção de saúde é relativamente recente, sendo que apareceu pela primeira vez ao público no século passado. No decorrer do seu desenvolvimento, este tema foi marcado pela tensão entre duas abordagens, uma mais individualizada e focada nos recursos médicos e outra mais orientada socialmente. Desde o relatório publicado pela Organização Mundial de Saúde (OMS), a Carta de Ottawa para a Promoção da Saúde, que esta é vista tanto como reflexo das condições sociais como dos comportamentos individuais. Ora, como refere Pamela Hartigan, "ser saudável é uma equação complexa onde interagem muitos factores" (Ratzan et al., 2000: 14 e 15).

Segundo dados da Comissão Europeia, a interacção entre ambiente e saúde é mais íntima do que comummente se pensa, estima-se que $20 \%$ das doenças nos países industrializados se devem a factores ambientais, como seja o cocktail de químicos a que estamos expostos no ar, na água e na comida. Assim sendo, é cada vez mais intensa a preocupação dos cidadãos com os potenciais impactos que o ambiente tem sobre a saúde, pelo que a Comissão Europeia criou a Estratégia Europeia de Ambiente e Saúde, que defende uma abordagem integrada na resolução dos assuntos de saúde ambiental. Este programa tem como objectivos: reduzir o peso das doenças criadas por factores ambientais na UE, com especial ênfase em grupos vulneráveis como as crianças; identificar e prevenir novas ameaças à saúde causadas por factores ambientais; e 
fortalecer a capacidade da UE em políticas na área (Comissão das Comunidades Europeias, 2005).

Em 1986 realizou-se a primeira conferência internacional de promoção da saúde, que defendeu que

A promoção de saúde passa pela capacitação dos indivíduos para o controlo e melhoria da sua saúde. Para alcançar um estado de completo desenvolvimento físico, mental e bem-estar social, um indivíduo ou grupo deve ser capaz de identificar e realizar aspirações, satisfazer necessidades e interagir com o ambiente. (...) Por conseguinte, a promoção da saúde não é apenas responsabilidade do Sector de Saúde, mas antes pressupõe estilos de vida saudáveis que contribuam para o bem-estar de forma generalizada (Organização Mundial de Saúde, 1986).

Neste relatório afirma-se que, uma vez que as condições e recursos fundamentais para a saúde são tão abrangentes (paz, abrigo, educação, alimentação, rendimento, sistema ecológico estável, recursos sustentáveis, justiça e equidade social), a melhoria da saúde requer alicerces seguros nas várias dimensões. É capital uma visão holística da saúde: "Os pré-requisitos e perspectivas para a saúde não podem ser assegurados apenas pelo Sector de Saúde. Mais importante será a acção concertada de todos os intervenientes: governos e demais organismos sociais e económicos, organizações não governamentais, autoridades locais, indústria e comunicação social. Todos os indivíduos se vêem, deste modo, envolvidos", acrescenta-se no documento assinado na capital do Canadá. Por sua vez, uma vida salutar é um garante para o desenvolvimento pessoal, social e económico, pelo que a protecção do ambiente e a conservação dos recursos naturais deverá estar presente nas estratégias de promoção da saúde e de crescimento dos vários países e nações. Pela primeira vez, a Carta de Ottawa expressou a ideia de que um ecossistema estável e consequentes recursos sustentáveis são pré-requisitos para a saúde.

Segundo Julio Frenk, "A saúde é uma encruzilhada, visto ser o local de convergência de todos os factores biológicos e sociais, do indivíduo e da comunidade, da política social e da economia. (...) Além do seu valor intrínseco, a saúde é um meio para o avanço pessoal e colectivo. É, portanto, um indicador do sucesso alcançado por dada sociedade e suas instituições governamentais na promoção do bem-estar, visto este último como o sentido último do desenvolvimento" (Frenk, 1993: 469). O referido autor desenvolve o conceito de saúde pública, defendendo que esta se deve modernizar, abrindo-se aos demais campos.

Frenk não está sozinho da sua tese, na conferência de 2004 da OMS, ficou escrito que "Estamos particularmente preocupados com as doenças provocadas por riscos ambientais, fardo este que detém sérios impactos na saúde pública a nível internacional" (Organização Mundial de Saúde, 2004: 1). Segundo a OMS, as crescentes consequências climáticas requerem uma resposta proactiva e multidisciplinar dos governos e das organizações internacionais. A OMS defende que a protecção da saúde pública e do ambiente exige previsão, transparência e participação democrática significativa das partes interessadas nos processos decisórios, pelo que se compromete a reforçar a sua colaboração a fim de apoiar as acções destinadas a melhorar o ambiente e a situação da saúde na Comunidade dos Estados Independentes, bem como em outras áreas que necessitam de atenção especial, como os países do Sudeste da Europa.

Mais concretamente, a OMS defende a necessidade de um sistema de informação e de pesquisa independente em saúde e ambiente, para que as decisões políticas possam ser bem fundamentadas (exemplo disto é a referência no artigo citado da produção e comercialização de grandes quantidades de produtos químicos, com efeitos pouco 
conhecidos para a saúde humana e para o ambiente). Deve-se igualmente avaliar bem os impactos económicos dos diferentes níveis de degradação ambiental, em especial os custos directos e indirectos suportados pela sociedade no tratamento de doenças relacionadas com o ambiente.

Os estilos de vida da população, as condições sociais dos cidadãos, o parque habitacional existente e as suas imediações devem ser considerados no desenvolvimento de políticas de habitação saudável e sustentável. Esta organização incentiva ainda o uso sustentável e adequado de energias renováveis. Os seus propósitos podem ser sintetizados no excerto seguinte: "Vamos fazer pleno uso das nossas comissões nacionais de desenvolvimento sustentável para alcançar as metas da OMS, de modo a integrar a saúde nos planos de desenvolvimento sustentável, colaborar com outros sectores sociais e a prestar assistência de forma abrangente" (Organização Mundial de Saúde, 2004: 9).

$\mathrm{Na}$ obra de 2000, Alcançar a Saúde Global: Desafios e Oportunidades, é de destacar a mudança de padrão dos perigos para a saúde:

As ameaças ambientais para a saúde humana podem ser divididas em "perigos tradicionais”, associados a um baixo nível de desenvolvimento económico, e "perigos modernos", relativos à industrialização. Os primeiros estão relacionados com a pobreza e o baixo nível de desenvolvimento económico e incluem: falta de acesso a água potável; saneamento inadequado; poluição do ar no interior das habitações devido ao uso de carvão e de biomassa; e eliminação inadequada de resíduos sólidos. Os perigos modernos estão relacionados com o desenvolvimento económico sem a adequada salvaguarda da saúde e do ambiente, bem como com o aumento do consumo dos recursos naturais. Esses riscos incluem: poluição da água, agricultura intensiva, poluição do ar pelos veículos a motor; alterações climáticas e destruição da camada de ozono (Ratzan et al., 2000: 14).

Se ainda restavam dúvidas sobre a influência do meio envolvente na qualidade de vida do ser humano, do prefácio da obra Ecologia da Saúde destaca-se a afirmação: "Ecologia humana perfaz a totalidade das interacções relacionadas com o ser humano e o meio ambiente, segundo uma visão holística de responsabilidade individual e de interrelações entre indivíduos e ecossistema envolvente" (Hanari et al., 1999). De acordo com os autores citados, o controlo da saúde é uma questão de profunda consciência, já que manter uma nação salutar requer equilíbrio e desenvolvimento sustentado no seio das variadas instituições que influenciam a saúde.

Nota-se uma crescente compreensão e aceitação, tanto a nível pessoal como intelectual, de que tudo está ligado entre si. Há uma percepção exponencial de que o mundo é interactivo e dinâmico, pelo que se torna cada vez mais claro que os estudos tradicionais não abarcam paradigmas adequados à compreensão de fenómenos complexos, tais como a saúde, a cultura e as interacções entre o Homem e Natureza (Hanari et al., 1999: 1).

Na mesma obra questiona-se: "Como se cria a saúde? (...) Os indivíduos criam saúde interagindo uns com os outros e com os seus ambientes físicos. Uma estratégia de saúde pública deve, assim, começar pelas definições da vida quotidiana em que a saúde se insere" (idem: 50). Resumindo, pelas palavras de Ilona Kichbusch, "Saúde descreve a interacção entre os seres humanos e o seu meio ambiente" (idem: 56). 


\section{Conceitos de saúde e doença}

A área conhecida hoje como Sociologia da Saúde e da Doença consiste no resultado de uma evolução de cerca de cinco décadas, desde que a Sociologia começou a prestar atenção à medicina, na década de 50. Na altura, o enfoque centrava-se no hospital e na profissão médica. Já nos anos 70, a Sociologia alargou a sua área de estudo aos contextos profissional e familiar, enquanto originários das desigualdades. Esta evolução deve-se: à compreensão de que os cuidados de saúde não conseguem dar resposta definitiva às doenças que, com o envelhecimento populacional, começam a marcar a condição dos indivíduos; a influências marxistas que questionam as relações entre médico e paciente; e a mudanças no funcionamento do sistema de saúde e suas relações com as esferas política, económica e social (Cabral et al., 2002).

Com efeito, na segunda metade do século XX, Portugal assiste a mudanças demográficas, políticas, científicas e sociais que se inter-relacionam. Verifica-se a descida da mortalidade infantil e o controlo das doenças infecciosas, com o consequente aumento da esperança média de vida. O que, por sua vez, levou ao aumento exponencial do peso da população vulnerável às doenças crónicas e degenerativas associadas à velhice. Por seu turno, os movimentos higienistas contribuíram para que a saúde passasse a fazer parte das prioridades dos governos das democracias liberais. Contudo, assiste-se ao posterior recuo da aposta do Estado em assegurar um sistema de saúde universal e gratuito, incentivando a partilha da gestão do referido sistema com o sector privado.

Ainda a nível nacional, assinalam-se avanços na medicina, na farmacologia e no crescimento dos cuidados de saúde. Tais mudanças contribuíram para a desvalorização dos factores ambientais, sociais e psicosociais na explicação e prevenção das doenças. A estratégia política de melhoria da saúde pública e individual passaria então a reduzir-se ao aumento da oferta e qualidade dos serviços de saúde e de medicamentos, notando-se a tendência para a valorização da "cura" em detrimento da "prevenção". No plano social, persiste uma subida generalizada dos salários e melhorias na habitação e urbanismo, bem como o aumento dos níveis de escolaridade e a democratização do acesso à cultura. Esta situação favorável conduz à valorização da saúde não só enquanto condição física mas também como equilíbrio psicológico e social. A emergência de um forte discurso individualista, com a importância da responsabilidade individual (comportamentos saudáveis) e a desvalorização do papel das instituições são a consequência da presente tendência.

Ainda segundo a obra de Manuel Villaverde Cabral, nos últimos vinte anos notam-se crescentes desigualdades no acesso à saúde, apesar de esta ser a área em que o Estado mais investe. Como se explica esta aparente incongruência? Visto boa parte dos gastos do sistema de saúde serem empregados na aquisição de equipamentos de alta tecnologia, medicamentos, salários dos profissionais de saúde e para o funcionamento da burocracia administrativa. Ou seja, o problema prende-se na distribuição dos recursos pelos diferentes níveis do sistema de Saúde. Quando a prioridade do sistema se centra em princípios de efectividade e eficiência, e não na equidade, depreende-se que os investimentos não tenham tradução automática na redução das desigualdades.

Desde o século XIX que o indicador da mortalidade é utilizado como medida de referência para analisar o estado das desigualdades perante a saúde, visto lidar com factos inequívocos que geralmente exigem uma declaração oficial, permitindo desta 
forma padronizar os dados. Contudo, com o envelhecimento populacional, o conceito de morbilidade tem vindo a ganhar terreno. Este segundo indicador, por sua vez, é mais difícil de analisar, por ser subjectivo e envolver julgamentos pessoais relacionados com expectativas e exigências culturais (segundo a obra referida anteriormente, os mais desfavorecidos tendem a subdeclarar doenças crónicas).

As desigualdades sociais, longe de estarem distribuídas de forma aleatória, atingem, de forma sistemática, grupos desfavorecidos, uma vez que as condições materiais e sociais de vida das populações originam alterações no organismo com consequências patológicas. Sally Macintyre defende que "Em todas as sociedades conhecidas, os comportamentos relacionados com a saúde física e mental e respectiva expectativa de vida tendem a variar entre os grupos sociais. Os eixos principais de variação incluem variantes como o estatuto socioeconómico, o género, a etnia e o local de residência" (Macintyre, 2007: 1). Segundo a autora, as desigualdades devem-se a: "Exposições específicas - como sejam profissões de risco, alojamento precário ou demais eventos adversos -; comportamentos - de que são exemplo as práticas de exercício físico, dieta alimentar ou comportamentos de risco como o tabagismo e o alcoolismo -, e forças ou vulnerabilidades pessoais - sejam eles resiliência ou capacidade de planear o futuro". Contudo, para Macintyre, as causas fundamentais prendem-se com as políticas internacionais, com as forças económicas e com as formas de estratificação social de uma dada sociedade.

O Relatório Black (Townsend e Davidson, 1982) foi pioneiro nesta ligação de ideias, usando variáveis para entender as desigualdades, onde se destacam: escolaridade, rendimento, prestígio social da ocupação, nível de inserção em redes sociais, condições materiais do alojamento, género, etnia, idade.

Em relação à variável rendimento, um estudo americano cujo título encontra tradução em Análise dos Múltiplos Factores de Risco concluiu que "os valores relativos à mortalidade desciam de forma regular à medida que se subia de escalão de rendimento" (Macintyre, 2007: 41). Também Kunst e Mackenbach fizeram uma investigação em nove países industrializados que levou à conclusão de que "a ordem dos países em termos de desigualdade de rendimento corresponde à sua ordem em termos de desigualdade de mortalidade" (Macintyre, 2007: 46). Van Doorslaer considerou que a auto-avaliação do estado de saúde varia em função da distribuição de rendimento, sendo que "nos países com uma distribuição de rendimento mais igualitária, era menor a variação da autoavaliação do estado de saúde entre grupos sociais inquiridos" (Macintyre, 2007: 46).

Já relativamente à variável trabalho, é sabido que as condições e a organização do trabalho têm um impacto indirecto mas cumulativo sobre a saúde do indivíduo. Locker alertou para a importância dos "efeitos nocivos para a saúde das condições objectivas do desempenho de determinadas funções, sobretudo na indústria" (Macintyre, 2007: 47). "Os mais expostos são, de forma cumulativa, os trabalhadores menos qualificados, afectados por tarefas penosas e perigosas" (Macintyre, 2007: 47), acrescentam Volkoff e Thébaud-Mony. Com efeito, os trabalhadores manuais continuam a ser os que mais sofrem com as mudanças do mercado de trabalho. O actual crescimento da "precarização" do emprego e o aumento do desemprego levam a questionar quais serão as influências na esperança de vida da presente geração.

Sob o prisma da variável escolaridade, considera-se que os indivíduos com maior escolaridade têm maior capacidade para responder a campanhas de prevenção e promoção de saúde. Esta variável é muito importante, pois estrutura as hipóteses de 
vida dos indivíduos, condicionando a carreira profissional e o rendimento que estes irão receber. Mackenbach fez um estudo na Holanda que revelou que, "à medida que sobe a escolaridade dos inquiridos, menor é a incidência de doenças crónicas e melhor a saúde auto-avaliada" (Macintyre, 2007: 49). Calwell conduziu uma análise interessante, que revelou existirem "países como o Sri Lanka, que, apesar do seu baixo rendimento per capita, alcançam valores na esperança de vida muito próximos do "primeiro mundo» por influência da educação da população, sobretudo feminina" (Macintyre, 2007: 50), uma vez que as mulheres desempenham geralmente o papel de garantes familiares.

Estilo de vida é outra variável referida na obra Saúde e Doença em Portugal, sendo que diz respeito à influência dos comportamentos individuais sobre a saúde e a doença. Stroebe realizou vários estudos sobre os hábitos salutares e preventivos dos indivíduos, concluindo que a dieta e o exercício físico se relacionam com doenças cardiovasculares; o comportamento na estrada com os acidentes; o consumo de tabaco com o cancro do pulmão; o consumo de álcool com a cirrose hepática; o comportamento sexual com a transmissão da sida, e assim por diante (Macintyre, 2007: 59). Este autor acredita que a prevenção primária é uma estratégia de saúde mais efectiva do que a alteração de comportamento, já que a irresponsabilidade individual, a falta de vontade e/ou motivação para mudar, a ausência de informação/compreensão da linguagem da prevenção e do risco dificultam a alteração dos hábitos nocivos para a saúde.

Relativamente à variável género, na sociedade portuguesa, as mulheres vivem mais do que os homens mas apresentam índices de morbilidade mais altos. Paralelamente, notase a tendência para as primeiras sobredeclararem e os segundos subdeclararem as doenças. Grand afirma que "tanto na mortalidade como na morbilidade, os homens apresentam entre si desigualdades mais acentuadas do que as mulheres, um fenómeno eventualmente explicado pelo facto de o lugar das mulheres na hierarquia social não se resumir tanto, como acontece nos homens, ao seu lugar na produção" (Macintyre, 2007: 65). Contudo, à medida que os modos de vida se aproximam (ocupação, comportamentos de risco), também os níveis de esperança média de vida. Além de que as desigualdades do género se relacionam com as desigualdades socioeconómicas.

Por fim, interessa referir a variável idade, sendo que o estado de saúde do idoso é o resultado cumulativo de todas as influências que afectaram o seu percurso de vida desde a infância. Os indivíduos com menor escolaridade, menores rendimentos e que tiveram ocupações sobretudo manuais possuem níveis de morbilidade sistematicamente mais elevados do que aqueles que se encontram no topo da hierarquia social. Contudo, são os mais ricos que gastam mais dinheiro em medicamentos - esta é a chamada lei dos cuidados inversos (Macintyre, 2007: 65). Com efeito, "as desigualdades na mortalidade persistem nas faixas etárias mais altas, e porque a maioria da mortalidade ocorre em idades mais avançadas, a desigualdade na mortalidade entre os idosos não é menos importante do que nas faixas etárias mais jovens" (Mackenbach, 2006: 13).

\section{Os determinantes da saúde}

Depois de analisadas as variáveis que explicam o acesso diferenciado à saúde, urge dissecar melhor o próprio conceito de saúde, de modo a estudar em profundidade esta temática. 
Winslow definiu saúde pública como a ciência e a arte de prevenir doenças, prolongar a vida e promover a saúde física e mental, bem como a eficiência dos esforços comunitários de saneamento do ambiente, controlo de infecções comunitárias, educação das populações segundo princípios de higiene pessoal, organização de serviços de medicina e enfermagem que garantam diagnósticos prévios e tratamento de doenças, e o desenvolvimento de instituições sociais que assegurem um padrão de vida adequado à manutenção da saúde de cada indivíduo da comunidade (Hanari et al., 1999: 38).

Segundo José Coura, "o conceito de saúde tem evoluído ao longo dos anos, desde a sua interpretação mais simples e antiga como a "ausência da doença» até à concepção abrangente da Organização Mundial de Saúde, de um «estado de completo bem-estar físico, mental e social»". Contudo, o autor considera esta descrição ainda incerta, propondo a definição do conceito de saúde como "a completa adaptação do Homem ao meio, preservando a sua integridade física, mental e social" (Carvalheiro et al., 2002: 29).

A obra citada aborda a situação da saúde brasileira, afirmando-se que "o caminho a percorrer (...) ainda é longo e difícil" (Carvalheiro et al., 2002: 27). "Desde que a saúde foi reconhecida como um direito do Homem, pela Declaração de Princípios da Declaração Mundial de Saúde (1948), os governos e a sociedade ficaram implícita e moralmente obrigados a desenvolver estruturas de promoção, protecção e recuperação da saúde, capazes de atender a todos adequadamente, em seus respectivos países. Ocorre, entretanto, que o desejo, a determinação e a possibilidade de atender ao compromisso assumido quase sempre estiveram dissociados na maioria dos países que o assumiram" (Carvalheiro et al., 2002: 30). O que explica dever tanto à falta de recursos materiais e humanos como ao mau planeamento político e à falta de um sistema de saúde no Brasil. "É inegável que a saúde é um direito fundamental do ser humano (...) mas também é verdade que a saúde tem um custo financeiro, de organização e de decisão política que muitos países do terceiro mundo não podem pagar" (idem: 31), afirma José Coura. Assim sendo, o poder económico das nações está directamente relacionado com a saúde das respectivas populações, uma vez que "a pobreza continuará a ser o principal problema a resolver para a protecção da saúde" (idem: 33). Ainda segundo este aspecto, Francisco Salzano fala da "distância entre as boas intenções e a fria realidade dos recursos financeiros" (idem: 40).

Apesar das exigências financeiras, tem havido avanços importantes no campo da saúde. A Comissão das Comunidades Europeias fala numa "evolução cabal dos sistemas de cuidados de saúde, em parte resultante do rápido desenvolvimento de novas tecnologias que estão a revolucionar as modalidades de promoção da saúde e de previsão, prevenção e tratamento das doenças. Neste contexto, são de referir, nomeadamente, as tecnologias da informação e comunicação (TIC), a inovação genómica, a biotecnologia e a nanotecnologia." (Comissão das Comunidades Europeias, 2007: 3). Estes aspectos inscrevem-se no objectivo estratégico geral de prosperidade visado pela Comissão, de forma a garantir um futuro competitivo e sustentável para a Europa.

Para que seja possível envelhecer com saúde tornam-se necessárias acções de promoção da saúde e de prevenção da doença ao longo de todo o ciclo de vida dos indivíduos, que abordem questões como a má-nutrição, o exercício físico, o consumo de álcool, drogas e tabaco, os riscos ambientais, os acidentes rodoviários e domésticos. A melhoria da saúde das crianças, dos adultos em idade activa e dos idosos contribuirá para o desenvolvimento de uma população saudável e produtiva, 
e apoiará o envelhecimento com saúde, agora e no futuro. Do mesmo modo, ao tomar medidas de promoção de estilos de vida saudáveis, de redução de comportamentos nocivos e de prevenção e tratamento de doenças específicas, incluindo as doenças genéticas, contribuir-se-á para favorecer o envelhecimento saudável. Importa promover activamente a medicina geriátrica, dando particular atenção à prestação de cuidados individualizados. Os cuidados paliativos e uma melhor compreensão das doenças neurodegenerativas, como a doença de Alzheimer, são também necessidades importantes a que se deve dar resposta.

É igualmente apropriado aprofundar os trabalhos no domínio do sangue, dos tecidos, das células e dos órgãos, abordando as questões relativas aos transplantes. Para sustentar estas medidas, torna-se necessário intensificar a investigação, inclusivamente mediante estudos longitudinais, e aumentar as capacidades no domínio da saúde pública, por exemplo mediante o reforço das estruturas de formação e de saúde pública. Tendo em conta a crescente pressão sobre as finanças públicas resultante da evolução demográfica e de outros desafios, é fundamental garantir que as acções empreendidas sejam eficientes e eficazes." (Bruxelas, 2007: 8).

Este relatório de 2007 visa promover a saúde numa Europa envelhecida, através de sistemas de saúde dinâmicos e das novas tecnologias.

Poderá o mundo alcançar a saúde universal no século XXI? Eis o que se questiona na obra Alcançar a Saúde Global: Desafios e Oportunidades: “O século XX testemunhou uma revolução na saúde humana e no bem-estar. (...) Enquanto algumas ameaças à saúde diminuíram, outras surgiram, tais como o vírus do VIH e novas formas de cancro. Micróbios causadores de doenças tornaram-se resistentes aos medicamentos. Aspectos da vida moderna parecem incentivar os comportamentos pouco saudáveis, como o tabagismo e as dietas ricas em gordura" (Ratzan et al., 2000: 3). Ou seja, à medida que se verificam desenvolvimentos no combate às doenças, também estas vão sofrendo mutações, consequência dos novos estilos de vida.

“A transição da mortalidade nos países mais desenvolvidos envolveu uma mudança nas principais causas de morte por doenças transmissíveis, tais como sarampo, gripe e a varíola; para doenças crónicas e degenerativas, como é o caso de doenças cardíacas, cancro e enfisema. Esta alteração reflecte uma transição epidemiológica do estado de saúde" (Ratzan et al., 2000: 8). A esperança média de vida aumentou significativamente ao longo do século passado, mas esta realidade trouxe novos problemas, nomeadamente relacionados com a morbilidade.

$\mathrm{Na}$ obra já anteriormente referida defende-se que a descoberta dos microrganismos causadores das doenças infecciosas e o reconhecimento de que a sua transmissão podia ser evitada pela limpeza das mãos e dos instrumentos médicos revolucionou a prática médica. Actualmente, doenças como o cancro e o enfarte, mas também a depressão, a demência e a esquizofrenia, estão a aumentar a sua proporção. Ora, "cada tipo de problema exige uma estratégia diferente de prevenção e tratamento" (Ratzan, 2000: 25). Com efeito, à medida que desafios anteriores são ultrapassados, outros novos surgem.

Entretanto, é gritante a distância entre países desenvolvidos e países em desenvolvimento. Segundo Volney Garrafa, “apesar do espantoso desenvolvimento científico e tecnológico experimentado na segunda metade do século passado, mais de dois terços da população do planeta continua alijada dos benefícios alcançados" (Carvalheiro et al., 2002: 27). Aqui surge a noção do "hiato 10/90", ou seja, "mais de 70 biliões de dólares são anualmente aplicados na pesquisa em saúde no mundo, com 
recursos públicos e privados, mas apenas $10 \%$ dos mesmos recursos se destinam a doenças que atingem $90 \%$ da população mundial" (idem: 17 ).

As diferenças entre ricos e pobres reconhecem-se também porque "actualmente, os países pobres carregam um «duplo fardo» de doenças (...) não tendo ainda controlado as doenças transmissíveis, já estão assolados também pelas crónico-degenerativas" (Carvalheiro et al., 2002: 17).

Como Volney Garrafa defende, "as novas tecnologias e as informações estão, em grande parte, disponíveis. 0 problema prende-se no acesso às mesmas. Neste amargo mundo "globalizado», acho cada vez mais difícil tratar o tema sem o politizar, uma vez que a espécie humana já conseguiu dominar as técnicas para controlar a maioria dos problemas" (Carvalheiro et al., 2002: 21). As variáveis demográficas, as configurações socioeconómicas, as crenças culturais e os recursos médicos mostram como a saúde é vivida de maneira diferente consoante as diferentes realidades.

De onde vêm, então, as doenças? Para Maria Erler, deve-se investir no conhecimento científico, pois "a genética e a biologia molecular podem contribuir para a prevenção, controle, diagnóstico, tratamento e cura da maioria das doenças" (Carvalheiro et al., 2002: 39). Já José Neto tem uma opinião diferente, para o autor "a proporção de doenças atribuíveis somente a causas genéticas é relativamente pequena. (...) Mesmo reconhecendo a contribuição de factores genéticos, é importante destacar que diferenças na estrutura social, estilo de vida e factores ambientais continuam a ser responsáveis por uma proporção de doenças bem maior" (idem: 21).

Por sua vez, Victor Penchaszadeh afirma que:

a maioria da população mundial pode prevenir-se da maioria dos problemas de saúde actuais, com métodos conhecidos não genéticos: desenvolvimento económico e social sustentável e infra-estruturas de água potável e saneamento; justiça e equidade na distribuição das riquezas geradas pela actividade económica; aprovisionamento de alimentação, habitação e trabalho adequados; promoção de estilos de vida saudáveis, actividade física, redução do stress, diminuição da exposição a tóxicos e contaminantes ambientais; e efectivo direito à saúde (Carvalheiro et al., 2002: 36).

Assim sendo, quem é o responsável pela manutenção do estado de saúde? A presente obra apresenta uma visão interessante a este respeito: "A constituição brasileira de 1988, paternalista como é, diz «a saúde é um direito do povo e um dever do Estado». Na minha opinião, deveria dizer: «A saúde é um direito e um dever do povo e do Estado». Se o indivíduo se embriagar, fumar, usar drogas, adoecer, tiver um acidente, ferir ou matar outrem, somente o Estado é responsável pela sua saúde?" (Carvalheiro et al., 2002: 31). Francisco Salzano sintetiza: "somos todos responsáveis pela busca de um mundo mais saudável" (idem: 40).

Por sua vez, na obra Ecologia da Saúde, é afirmado o direito e o dever de o indivíduo agir sobre a sua saúde:

A percepção social de o risco está a mudar e está a influenciar a reacção dos indivíduos. Surgirão necessidades de acção a nível internacional, nacional e municipal, bem como propostas de estratégias individuais e movimentos de consumidores a favor da sustentabilidade. (...) A saúde das populações mudou com o crescimento económico e consequente amplificação da distribuição da riqueza, pressão para a mudança e reforma sociais, acção concertada em variados sectores e estabelecimento de um sistema de prevenção para a população em geral (Hanari et al., 1999: 54). 
Contudo, o papel das instituições não foi esquecido: "Os indivíduos podem melhorar a sua saúde a nível individual, mas tal atitude deve ser reforçada e apoiada por medidas do Sistema de Saúde" (Hanari et al., 1999: 52).

Um sistema de saúde ideal aposta na prevenção, através da informação, da educação, da vacinação e de comportamentos saudáveis e, sobretudo, na melhoria da qualidade de vida das populações, almejando o fim da pobreza. "Idealmente, o fornecimento de informação e de serviços de saúde passaria do hospital para casa e da cura para a prevenção e respectivos cuidados pessoais" (Ratzan et al., 2000: 37).

É caricato pensar que na Feira Mundial de Nova Iorque, em 1893, especialistas previram que o homem viveria até aos 150 anos, até ao final do século XX (Ratzan et al., 2000: 38).

A questão “Poderá o mundo ser saudável?" não encontra resposta simples. Se concertássemos todos os recursos e esforços para superar a pobreza, seríamos ainda assolados por doenças infecciosas e não transmissíveis, embora a níveis mais diminutos. Não devemos deixar de ter como objectivo a saúde para todos, mas é certo que tal exigirá um compromisso e investimento no conhecimento científico para a criação de um novo conceito de "saúde ideal". Se nos esforçarmos por integrar a saúde em todos os sectores da sociedade e em gerar o mesmo nível de entusiasmo que se sente com o crescimento económico, poderemos enfim desenvolver um novo conceito de saúde (Ratzan et al., 2000: 44).

Concluindo, a saúde começa em casa, no trabalho, na escola, no governo e no ambiente. Mas, sobretudo, começa em cada um de nós (Ratzan et al., 2000: 44).

\section{Considerações finais}

A doença e o sofrimento físico tocam, de um modo geral, a todos. Contudo, como é referido na obra Ecologia da Saúde, "há muito a ter em conta além dos valores de morbilidade e mortalidade" (Hanari et al., 1999: 75).

Actualmente, a saúde é definida pela Organização Mundial de Saúde como aquilo que diz respeito ao estado de completo bem-estar físico, mental e social, e não apenas a anterior e limitada visão da ausência de doença ou enfermidade. Ora esta é uma definição positiva, uma vez que anteriormente uma pessoa sã era sinónimo de não estar doente, destacando-se uma acepção negativa do conceito. A contribuição da OMS introduz igualmente um factor dinâmico, que se vai moldando pelas vertentes internas que influenciam determinado estado de saúde. Por ser abrangente, a presente noção de saúde detém a capacidade de adaptação a diversas situações sem perder o objectivo. Contudo, tem sido alvo de críticas que a consideram utópica e inatingível.

Tal como o conceito de saúde, os conhecimentos tecnológicos e a prática clínica têm evoluído ao longo da História e constata-se que este progresso não é proporcional ou homogéneo nas várias partes do globo. Por outro lado, prevê-se que as iminentes alterações climáticas atingirão mais intensamente os países em desenvolvimento, justamente aqueles que não contribuíram para o estado de crise climática. Por isso se discutiu, aquando do Acordo de Copenhaga, sobre "responsabilidades diferenciadas" e ficou acordado que os países desenvolvidos deverão disponibilizar aos países em desenvolvimento " 30 biliões de dólares anuais entre 2010 e 2012" e "100 biliões de dólares anuais a partir de 2020" (Conferência das Nações Unidas sobre as Mudanças Climáticas, 2009). 
A medicina tem progredido no sentido de uma visão mais alargada do Homem, que passa a ser entendido não apenas na sua dimensão física mas também como ser social e cultural. Deste modo, a política de saúde terá de se ocupar dos problemas variados que as referidas situações encerram, o que exige empenhamento profundo, resolução atempada dos problemas, estudo de casos e conhecimentos a nível jurídico e sociocultural. Como é referido na obra de Göran Dahlgren e Margaret Whitehead, "uma das estratégias mais eficazes consiste precisamente em integrar objectivos de saúde equitativos nos mais variados campos: políticas socioeconómicas, programas para o crescimento económico, impostos, emprego, educação, habitação, serviços sociais, transportes, serviços de saúde, entre outros" (Dahlgren e Whitehead, 2006: 100).

A nível nacional, os problemas que se situam ao nível do SNS - como é o caso da relação médico/ paciente, a relação de doenças com o meio ambiente e com padrões culturais, ou o estudo de comunidades profissionais - requerem ainda alguma investigação e análise.

Paralelamente, assiste-se ao intensificar do interesse, e consequente procura, de métodos alternativos e complementares ao presente sistema de saúde, como sejam as práticas orientais de Reiki, Yoga, Acupunctura, Shiatsu, Reflexologia e Ayurveda, condizentes com um estilo de vida mais meditativo e consciente de que tudo está ligado a tudo (Hanari et al., 1999).

O conceito de saúde evidencia um grau de interdependência com sectores variados, onde se destacam o grau de desenvolvimento económico, a educação, a cultura, a segurança social, o ambiente, a habitação, os transportes ou ainda a saúde animal. Contudo, o acesso a determinados cuidados de saúde continua a depender das decisões políticas de cada país, da importância que o governo lhes atribui em termos de Orçamento de Estado e de políticas de incentivo e não apenas do referido desenvolvimento económico. Desta forma, um país com boas condições económicas e com uma razoável distribuição de rendimentos, em princípio, proporciona níveis gerais da condição de vida que favorecem a recuperação da doença e a manutenção da saúde. A saúde, enquanto direito fundamental inerente à condição humana, continua a caminho da sua concretização plena.

\section{BIBLIOGRAFIA}

CABRAL, M. V. et al. (2002), Saúde e Doença em Portugal, capítulo Saúde e sociedade: enquadramento teórico, Lisboa, Imprensa de Ciências Sociais.

CARVALHEIRO, J. et al. (2002), o crucial debate da ciência no limiar do século 21, Rio de Janeiro, Associação Brasileira de Pós-Graduação em Saúde Colectiva.

COMISSÃO DAS COMUNIDADES EUROPEIAS (2005), A Estratégia Europeia de Ambiente e Saúde, Bruxelas, Comissão Europeia.

COMISSÃO DAS COMUNIDADES EUROPEIAS (2007), Livro Branco, Juntos para a saúde: uma abordagem estratégica para a Europa, Bruxelas, Comissão Europeia. 
CONFERÊNCIA DAS NAÇÕES UNIDAS SOBRE AS MUDANÇAS CLIMÁTICAS (2009), Acordo de Copenhaga, Copenhaga.

DAHLGREN, G. e M. Whitehead (2006), Um documento de reflexão sobre estratégias europeias para a diminuição das desigualdades sociais em saúde (part 2), Liverpool, Organização Mundial de Saúde.

FRENK, J. (1993), Nova Saúde Pública, Massachusetts, Instituto Nacional de Saúde Pública.

HANARI, M., et al. (1999), Ecologia da Saúde: Saúde, Cultura e Interacção Homem/Ambiente, Londres, Routledge.

MACINTYRE, S. (2007), As desigualdades da saúde na Escócia: Quais são e o que podemos fazer sobre elas?, Glasgow, Concelho de Pesquisa Médica, Univ. Ciências de Saúde Pública \& Social.

MACKENBACH, J. (2006), Desigualdades na Saúde: perfil da Europa, Roterdão, Centro Médico Universitário de Roterdão.

ORGANIZAÇÃo MUNDIAL DE SAÚDE (1986), Carta de Ottawa para a Promoção da Saúde, Primeira Conferência Internacional para a Promoção da Saúde, Ottawa.

ORGANIZAÇÃO MUNDIAL DE SAÚDE (2004), Quarta Conferência Ministerial sobre Meio Ambiente e Saúde, Budapeste.

RATZAN, S., et al. (2000), Alcançar a Saúde Global: Desafios e Oportunidades, Washington, Population Reference Bureau.

\section{RESUMOS}

O ambiente influencia a saúde de variadas maneiras: através da exposição a factores de risco físicos, químicos e biológicos, e através de alterações relacionadas com o comportamento dos indivíduos em resposta aos mesmos factores. As actividades humanas estão a afectar o clima, com implicações graves para a saúde pública. Neste sentido, a construção de uma política de saúde integrada constitui um dos grandes desafios das sociedades contemporâneas. A presente temática começa a fazer parte tanto de propostas e projectos de empresas privadas, como de políticas públicas, visto a sustentabilidade apenas funcionar quando todos os aspectos da sociedade estão concertadamente envolvidos.

The environment influences our health in many ways: through exposure to physical, chemical and biological risk factors and through changes related to our behaviour in response to these factors. Human activities are affecting the climate, with serious implications for public health. In this sense, the construction of an integrated health policy is one of the great challenges of contemporary societies. This subject becomes part of both proposals and projects from private companies, as public policy, since sustainability works only when all aspects of society are involved in concert.

\section{ÍNDICE}

Keywords: health, disease, environment, ecology

Palavras-chave: saúde, doença, ambiente, ecologia 


\section{AUTORES}

\section{INÊS MEIRA}

Mestrado em Ecologia Humana, pela FCSH, UNL, inesgmeira@hotmail.com

ANA PATRÍCIA CARVALHO

Mestrado em Ecologia Humana, pela FCSH, UNL, anapatricia_carvalho@hotmail.com 